\title{
Fingerprint analysis of phenolic acid extract of Salvia miltiorrhiza by digital reference standard analyzer with one or two reference standards
}

\author{
Qingjun Wang ${ }^{1,2+}$, Xinlan $\mathrm{Yu}^{3 \dagger}$, Lei Sun ${ }^{1,3,4^{*}}$, Runtao Tian ${ }^{5}$, Huaizhen $\mathrm{He}^{4}$, Sicen Wang ${ }^{4}$ and Shuangcheng Ma ${ }^{1 *}$
}

\begin{abstract}
Background: Fingerprint analysis and simultaneous multi-components determination are crucial for the holistic quality control of traditional Chinese medicines (TCMs). Yet, reference standards (RS) are often commercially unavailable and with other shortages, which severely impede the application of these technologies.

Methods: A digital reference standard (DRS) strategy and the corresponding software called DRS analyzer, which supports chromatographic algorithms, spectrum algorithms, and the combination of these algorithms, was developed. The extensive function also enabled the DRS analyzer to recommend the chromatographic column based on big data.

Results: Various quality control methods of fingerprints of 11 compounds in polyphenolic acid extract of Salvia miltiorrhiza (S. miltiorrhiza) were developed based on DRS analyzer, involving relative retention time (RRT) method, linear calibration using two reference substances (LCTRS) technique, RRT combined with Photon Diode Array (PDA) method, LCTRS combined with PDA method. Additionally, the column database of samples was established. Finally, our data demonstrated that the DRS analyzer could accurately identify 11 compounds of the samples, using only one or two physical RSs.
\end{abstract}

Conclusions: The DRS strategy is an automated, intelligent, objective, accurate, eco-friendly, universal, sharing, and promising method for overall quality control of TCMs that requires the usage of fewer RSs.

Keywords: Substitute reference standards, digital reference standard (DRS), Relative retention time (RRT), Linear calibration using two reference substances (LCTRS), Fingerprints

\section{Background}

Due to good pharmacological activities and excellent curative effects, traditional Chinese medicine (TCMs) is increasingly popular not only in China but also around the world. Therefore, ensuring the efficient and safe use

\footnotetext{
*Correspondence: dasunlei@sina.com; masc@nifdc.org.cn

${ }^{\dagger}$ Qingjun Wang and Xinlan Yu contributed equally

${ }^{1}$ National Institutes for Food and Drug Control, Beijing, China

${ }^{4}$ Xi'an Jiaotong University, School of Medicine, Xi'an, China

Full list of author information is available at the end of the article
}

of TCM is an important issue. Given the complex components of TCMs, it is crucial to carry out a holistic quality control methodology, involving fingerprint technology and multi-components determination technology [1-4]. However, these technologies cannot be realized without reference standard (RS), which has brought great pressure to both providers and users. Firstly, the high price of RS led to a significant increase in the cost of TCM analysis. Besides, some TCM compounds are difficult to be extracted, isolated, and purified, while some are unstable and toxic, all of which lead to problems to the supply of

(c) The Author(s) 2021. This article is licensed under a Creative Commons Attribution 4.0 International License, which permits use, sharing, adaptation, distribution and reproduction in any medium or format, as long as you give appropriate credit to the original author(s) and the source, provide a link to the Creative Commons licence, and indicate if changes were made. The images or other third party material in this article are included in the article's Creative Commons licence, unless indicated otherwise in a credit line to the material. If material is not included in the article's Creative Commons licence and your intended use is not permitted by statutory regulation or exceeds the permitted use, you will need to obtain permission directly from the copyright holder. To view a copy of this licence, visit http://creativeco mmons.org/licenses/by/4.0/. The Creative Commons Public Domain Dedication waiver (http://creativecommons.org/publicdomain/ zero/1.0/) applies to the data made available in this article, unless otherwise stated in a credit line to the data. 
RS. Furthermore, due to the low content of these compounds in TCMs, the preparation of the RS requires a large quantity of TCMs and organic solvents, which is not eco-friendly.

The substitute RS method has been developed as a feasible solution for the problems discussed above. Substitute RS is a method for the qualitative or quantitative determination of another one or more compounds to be measured by one or a few physical RS by using several constant eigenvalues and algorithms [5-8]. Qualitative substitute RS methods include relative retention time (RRT) technique [9-12], extractive reference substance (ERS) method [8-11], linear calibration using two reference substances (LCTRS) approaches [13-15] and Photon Diode Array (PDA) spectrum method [16-18]. Quantitative methods include the relative correction factor method [9-12] and the quantitative ERS technique [9-11]. These methods not only promote the application of multi-components determination and fingerprint analysis for quality control of medicines but also have been proven to be more economical and simple [13-25]. However, the substitute RS method used in the holistic quality control of medicines still has some problems. In particular, the qualitative analysis of chromatographic peaks is the critical issue and the most challenging problem of substitute RS method. For this part, the RRT method and ERS method were adopted by the Pharmacopoeia of several countries, such as Chinese Pharmacopoeia, European Pharmacopoeia, etc. Yet, the drawbacks of the RRT method are large retention time $\left(t_{R}\right)$ deviation and poor column durability. Also, the reference chromatogram provided by only one chromatographic column by the method of ERS leads to the differences between the actual and reference chromatogram due to the various brands or types of columns. Consequently, scholars have studied the selectivity of reversed-phase columns [26], classified the columns [27, 28], and put forward the method of selection system of columns $[29,30]$ to solve the problem of blind selection of columns. Nonetheless, the problem of a large prediction deviation of the RRT method has not yet been fundamentally solved.

Compared with the RRT method, the LCTRS method could reduce the deviation of $t_{R}$ prediction [13-15]. However, there is still a challenge for improving the prediction accuracy of $t_{R}$, especially under the circumstances of different types of compounds, or with experiments that are conducted by columns with large differences in retention performance, which may even result in the reverse order of peaks [18]. PDA method may solve the problem of large deviation or reversed the order of peaks to some extent. However, it is difficult to effectively share data or objectively evaluate data in different laboratories, due to a lack of uniform PDA data exchange format among different brands of chromatography workstations $[16,17]$.

To solve these problems, we introduced the concept of the digital reference standard (DRS) in our previous study [31]. In the present study, a strategy for holistic quality control of TCM was proposed by the DRS analyzer using a phenolic acid extract of Salvia miltiorrhiza as an example. DRS analyzer is an algorithm software, which was developed to support the chromatographic algorithm methods of RRT and LCTRS, similarity algorithm of PDA spectrum, as well as the combination of different algorithms mentioned above. It is also a multidimensional database, which stores all the original data of the HPLC chromatogram and PDA spectrum during the establishment of the method. These data are not only useful for the calculation by software. Still, they are also crucial for searching and comparison of the chromatographic data by users, finally realizing the recommendation of column based on these data and improving the reproducibility and accuracy of the holistic quality control method. Phenolic acid extract of S. miltiorrhiza is the extract of Salviae Miltiorrhizae Radix (Danshen in Chinese), a popular TCM. Salviae Miltiorrhizae Radix is also used as a dietary supplement in other Asian countries, as well as in Europe and America. The design, algorithm, application, and characteristics of DRS analyzer were discussed in this study. Also, a series of quality control methods of fingerprint involving 11 compounds of polyphenolic acid extract of S. miltiorrhiza were developed based on DRS method.

\section{Methods}

\section{Chemicals and reagents}

The phenolic acid extract of S. miltiorrhiza was obtained from the National Institutes for Food and Drug Control (NIFDC, Beijing, China). RSs of Sodium Danshensu, Salvianolic acid D, and Lithospermic acid were purchased from Shanghai Yuanye Bio-Technology (Shanghai, China). Reference standards of Protocatechuic aldehyde, Caffeic acid, Rosmarinic Acid, Salvianolic acid B, Salvianolic acid H/I, Salvianolic acid E, Salvianolic acid L, and Salvianolic acid Y were obtained from NIFDC (Beijing, China).

Ethanol, which was analytical grade, was purchased from Sinopharm Chemical Reagent (Shanghai, China). Acetonitrile, methanol, phosphoric acid, and formic acid, which were chromatographic grade, were purchased from Fisher Scientific (Pittsburgh, PA, USA). 
Deionized water was prepared by a Milli-Q system (Millipore, Bedford, USA).

\section{Instruments and chromatographic conditions}

Chromatographic analysis was performed on Agilent 1260 high-performance liquid chromatography with a DAD detector, ChemStation online control, and offline analysis workstation (Agilent, Santa Clara, CA, USA). Twenty-two columns (Table 1) from seven manufacturers were randomly selected. It is recommended to use at least ten columns from three manufacturers for DRS method research.

Mobile phase A was $0.1 \%$ formic acid-water, and mobile phase B was $0.1 \%$ formic acid-acetonitrile. The elution procedure was as shown as below: $20-21.5 \%$ B for $0-30 \mathrm{~min}, 21.5-25 \%$ B for $30-35 \mathrm{~min}, 25-40 \%$ B for $35-45 \mathrm{~min}, 40-95 \%$ B for $45-50 \mathrm{~min}, 95-90 \%$ B for $50-53 \mathrm{~min}, 90-25 \% \mathrm{~B}$ for $53-60 \mathrm{~min}$. The detection wavelength was $288 \mathrm{~nm}$, and the UV-Vis absorption spectra (190-600 nm) were collected. Column temperature: $30^{\circ} \mathrm{C}$. Flow rate: $1 \mathrm{ml} / \mathrm{min}$. Injection volume: $10 \mu \mathrm{l}$.

\section{Preparation of sample and reference standard solution}

The solvent used to dissolve and storage the sample was $25 \%$ ethanol-water solution, with $\mathrm{pH}$ adjusted to 2.0 by

Table 1 Information of columns

\begin{tabular}{|c|c|c|c|}
\hline Code & Brand & Type & Specification \\
\hline Col1 & Agilent & Zorbax SB C 18 & $4.6 \times 250 \mathrm{~mm}, 5 \mu \mathrm{m}$ \\
\hline Col2 & Agilent & Zorbax $\mathrm{RX} \mathrm{C}_{18}$ & $4.6 \times 250 \mathrm{~mm}, 5 \mu \mathrm{m}$ \\
\hline Col3 & Shimadzu GL & Inertsil ODS-3 & $4.6 \times 250 \mathrm{~mm}, 5 \mu \mathrm{m}$ \\
\hline Col4 & Kromasil & Eternity- $5 C_{18}$ & $4.6 \times 250 \mathrm{~mm}, 5 \mu \mathrm{m}$ \\
\hline Col5 & Kromasil & $100-5 C_{18}$ & $4.6 \times 250 \mathrm{~mm}, 5 \mu \mathrm{m}$ \\
\hline Col6 & phenomenex & Luna $\mathrm{C}_{18}(2)$ & $4.6 \times 250 \mathrm{~mm}, 5 \mu \mathrm{m}$ \\
\hline Col7 & Shiseido & Capcell Pak $C_{18}$ SG120 & $4.6 \times 250 \mathrm{~mm}, 5 \mu \mathrm{m}$ \\
\hline Col8 & Shiseido & Superiorex $C_{18}$ & $4.6 \times 250 \mathrm{~mm}, 5 \mu \mathrm{m}$ \\
\hline Col9 & Shiseido & Capcell Pak $C_{18}$ ACR & $4.6 \times 250 \mathrm{~mm}, 5 \mu \mathrm{m}$ \\
\hline Col10 & Shiseido & Spolar $\mathrm{C}_{18}$ & $4.6 \times 250 \mathrm{~mm}, 5 \mu \mathrm{m}$ \\
\hline Col11 & Thermo & ODS-2 Hypersil $C_{18}$ & $4.6 \times 250 \mathrm{~mm}, 5 \mu \mathrm{m}$ \\
\hline Col12 & Thermo & Hypurity $\mathrm{C}_{18}$ & $4.6 \times 250 \mathrm{~mm}, 5 \mu \mathrm{m}$ \\
\hline Col13 & Waters & Xterra $\mathrm{MSC}_{18}$ & $4.6 \times 250 \mathrm{~mm}, 5 \mu \mathrm{m}$ \\
\hline Col14 & Waters & Atlantis T3 $\mathrm{C}_{18}$ & $4.6 \times 250 \mathrm{~mm}, 5 \mu \mathrm{m}$ \\
\hline Col15 & Waters & Sunfire $C_{18}$ & $4.6 \times 150 \mathrm{~mm}, 5 \mu \mathrm{m}$ \\
\hline Col16 & Waters & Xselect HSS $_{18}$ & $4.6 \times 250 \mathrm{~mm}, 5 \mu \mathrm{m}$ \\
\hline Col17 & Waters & Symmetry $C_{18}$ & $4.6 \times 250 \mathrm{~mm}, 5 \mu \mathrm{m}$ \\
\hline Col18 & Thermo & Hypersil gold & $4.6 \times 250 \mathrm{~mm}, 5 \mu \mathrm{m}$ \\
\hline Col19 & Agilent & Pursuit $C_{18}$ & $4.6 \times 250 \mathrm{~mm}, 5 \mu \mathrm{m}$ \\
\hline Col20 & Agilent & Agilent $\mathrm{HC}-\mathrm{C}_{18}(2)$ & $4.6 \times 250 \mathrm{~mm}, 5 \mu \mathrm{m}$ \\
\hline Col21 & Agilent & Agilent TC- $\mathrm{C}_{18}(2)$ & $4.6 \times 250 \mathrm{~mm}, 5 \mu \mathrm{m}$ \\
\hline Col22 & Agilent & Polaris $C_{18}$ & $4.6 \times 250 \mathrm{~mm}, 5 \mu \mathrm{m}$ \\
\hline
\end{tabular}

formic acid. The phenolic acids were relatively stable under this condition.

Appropriate amounts (above $16 \mathrm{mg}$ ) of phenolic acid extract of S. miltiorrhiza and $10 \mathrm{ml}$ solution mentioned above were put into a conical flask, shaken and filtered through a $0.22 \mu \mathrm{m}$ membrane before use.

An appropriate amount of $11 \mathrm{RSs}$, including sodium Danshensu, protocatechuic aldehyde, caffeic acid, salvianolic acid $D$, salvianolic acid $E$, salvianolic acid $H / I$, rosmarinic acid, lithospermic acid, salvianolic acid B, salvianolic acid $\mathrm{L}$, and salvianolic acid $\mathrm{Y}$ were dissolved by the solution mentioned above to obtain the reference standard solution.

\section{Software development \\ Data format}

DRS Analyzer supports the NetCDF (ANDI) data format [32], which is used for the exchanging and reading of chromatography and spectrometry data. The spectrum data from the PDA detector adopts an extended ANDI format [18]. HPLC instrument vendors such as Agilent and Waters have provided support for PDA spectrum exchanging with the extended ANDI format in their chromatographic workstation through macro or software upgrade.

\section{Program design}

DRS analyzer is developed with $\mathrm{C}++$ language, and Model View Controller (MVC) framework is adopted. It supports the chromatographic algorithm, PDA spectrum algorithm, as well as the combination of different algorithms mentioned above. The chromatographic algorithm includes the RRT method using one RS and the LCTRS method using two RSs. RRT is the ratio between $\mathrm{tR}$ of the analyte to the reference compound, which is the reference value for calculating the $t_{R}$ of an analyte. As RRT, $S t_{R}$ is also the reference value. But $S t_{R}$ is not the ratio; it is the arithmetic average of $t_{R}$ for the same compound on different HPLC systems under the same chromatographic conditions [14]. Also, there is a linear relationship between $t_{R}$ and $S t_{R}$ for all compounds [14], as shown in Fig. 1. For the LCTRS method, $t_{R}$ of the two RSs and $\mathrm{St}_{\mathrm{R}}$ are substituted into linear equation [as expressed in formula (1)] to calculate the $t_{R}$ of the analyte [14]. The similarity algorithm of the PDA spectrum is the cosine method [33].

In addition, the software is a multi-dimensional database, which stores all the original data of the HPLC chromatogram and PDA spectrum during the establishment of the method, and the recommendation of the column could be realized based on these data. The method of recommendation for the column is based on correlation, which is different from the existing recommendation method based on causation $[14,27-30]$ 


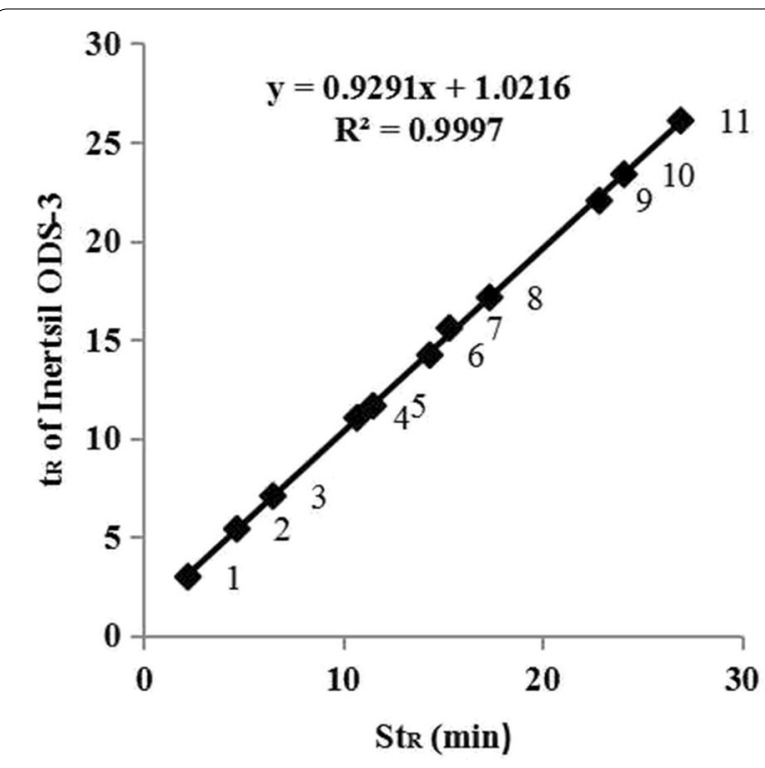

Fig. 1 Linear relationship between $t_{R}$ (Inertsil ODS-3) and $S t_{R}$. No. 1 to 11 represented Sodium Danshensu, Protocatechuic aldehyde, Caffeic acid, Salvianolic acid D, Salvianolic acid E, Salvianolic acid H/l, Rosmarinic acid, Lithospermic acid, Salvianolic acid B, Salvianolic acid $L$, and Salvianolic acid Y, respectively

$t_{R} c o l i=a \times S t_{R}+b$.

\section{Results}

\section{Optimization of HPLC conditions and method validation}

The mobile phase was investigated, including the separation effects of methanol and acetonitrile, the differences between phosphoric acid and formic acid, and the influences of column temperature. The gradient elution procedures and flow rates were optimized. The selected chromatographic conditions had good resolution, symmetrical peak shape, and reasonable analysis time. Chromatograms of samples were collected on 22 columns under optimized chromatographic conditions. Representative chromatograms and spectra are shown in Figs. 2, 3. The peaks were identified by the RSs, UV-Vis spectrum and mass spectrum.

Methodological validation experiments were performed on the Agilent Zorbax SB C18 column. The precision $(n=6)$, stability $(12 h, n=6)$, and repeatability $(n=6)$ were tested. The results showed that RSD of the $t_{R}$ of the 11 peaks and the peak areas were both less than $3 \%$, thus meeting the requirements of fingerprint analysis.

\section{Initialization for the DRS method}

Since the columns of number 1 to 17 could effectively separate 11 peaks of the samples, data on these columns were utilized to initialize the model by steps, as shown in Fig. 4. The first step was data importing. The chromatographic data and corresponding of the samples on columns 1 to 17 were imported into the software, and integration operations such as adding and deleting peaks were performed. The chromatographic data were in ANDI format, with the file name extension ".cdf". The spectral data were in extended ANDI format, with the file name extension ".nc". The PDA data was optional. The second step was the peak assignment. Names of the 11 compounds were input into the software, and then the corresponding peaks of the 17 columns and the compounds (the red box part of Fig. 5) were matched one-to-one. The third step was setting the qualitative chromatographic method, taking LCTRS as an example. The $t_{R}$ window of the peak was set to 1 minute. If the $t_{R}$ deviation for the peak was $\leq t_{R}$ window, the peak could

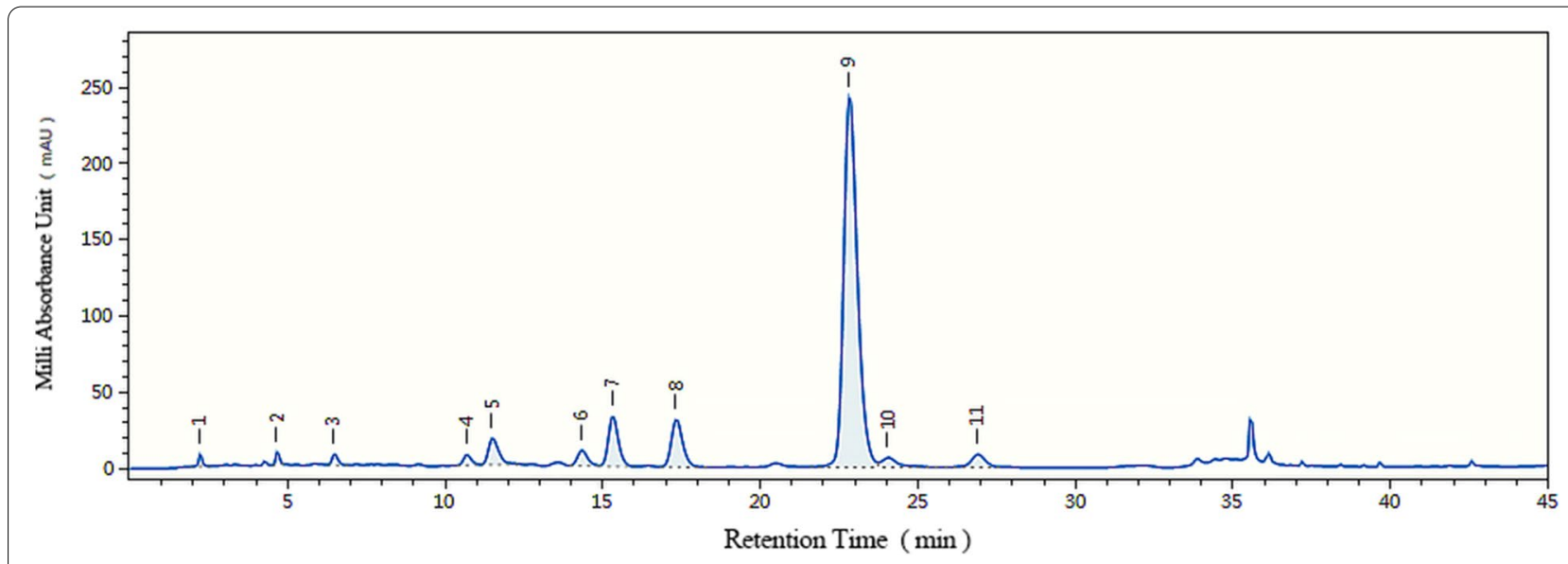

Fig. 2 Representative HPLC chromatogram of sample on Column 3 (Inertsil ODS-3). No. 1 to 11 represented the same compounds as Fig. 1 


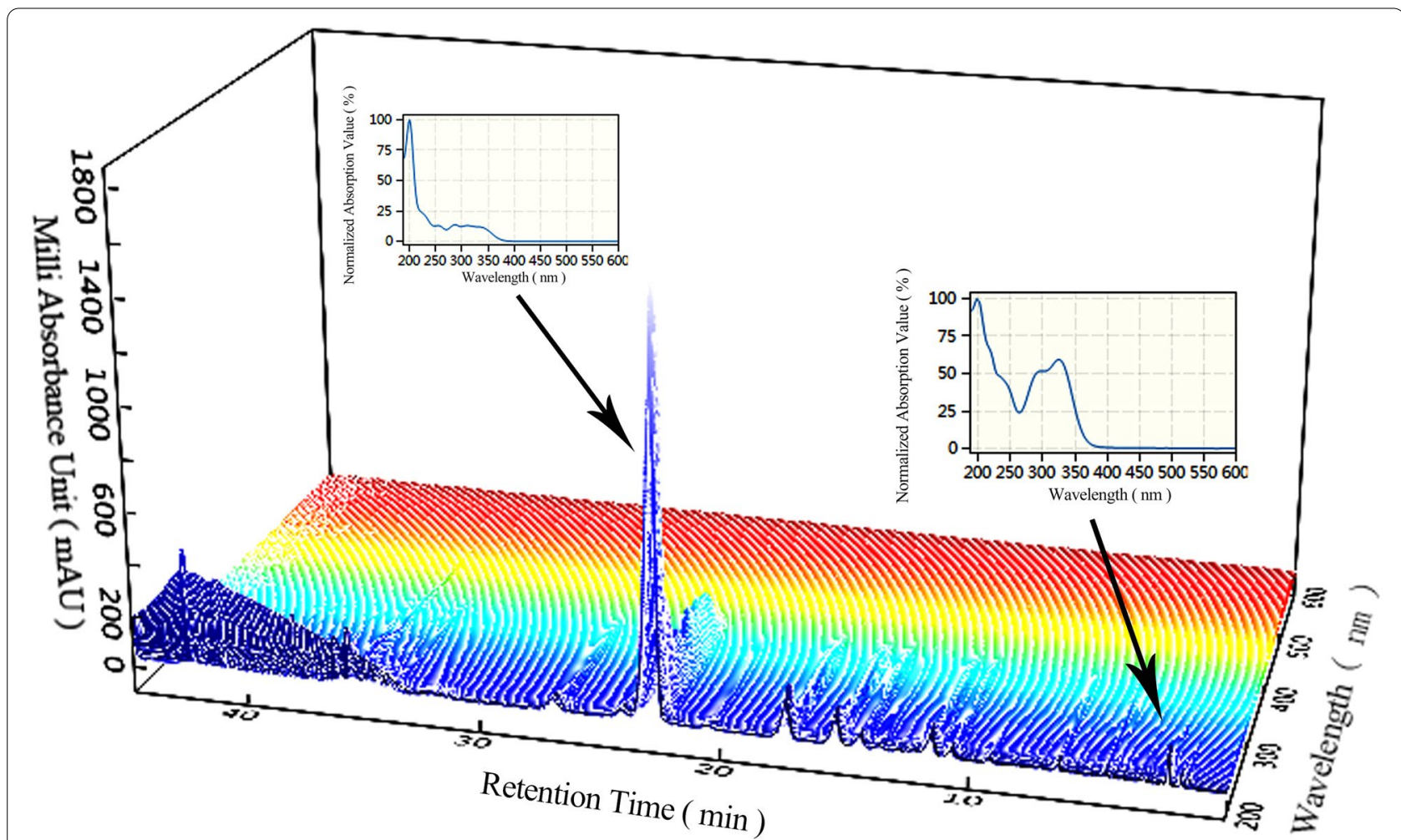

Fig. 3 Representative UV-Vis spectra of the sample

be identified. In this study, peak 1 and peak 9 (recommended to select the peaks close to the first peak and last peak respectively, including the first peak and last peak as well) were selected as two reference compounds, as shown in the green box of Fig. 5. The spectral data were available in the present study, and the fourth step was to establish a spectral qualitative method. As shown in the area of the blue box in Fig. 5, the synthesized spectrum was selected as a spectral matching method, and the similarity threshold was set to 0.95 .

\section{Optimization and evaluation of DRS method Selection of reference compound}

Since the selection of the reference compound can significantly affect the accuracy of the RRT and LCTRS method to calculate the $t_{R}$, the optimization was needed. According to our previous studies [14, 34], the general principles for RRT and LCRRS method to select reference compounds were as follows: the $t_{R}$ coverage of the reference compounds was $50-100 \%$, and their non-linear deviation was small enough. The coverage of $t_{R}$ was a reflection of the relative position of reference compound between the first compound and the last compound. For the LCTRS method and RRT method, the calculation of the coverage method was expressed in formula $(2,3)$, respectively. Since there were various marker compounds in the overall quality control method, even if following the above principle, a large amount of calculation was still required to obtain the optimal reference compounds for the sample under certain chromatographic conditions

$$
\text { Coverageoft } t_{R}=\frac{t_{R 2}-t_{R 1}}{t_{\text {Rlast }}-t_{R f i r s t}} .
$$

$t_{R 2}$ is $t_{R}$ (or $S t_{R}$ ) of second reference compound; $t_{R 1}$ is $t_{R}\left(\right.$ or $S t_{R}$ ) of first reference compound; $t_{R l a s t}$ is $t_{R}$ (or $S t_{R}$ ) of last compound; $t_{R \text { first }}$ is $t_{R}$ (or $S t_{R}$ ) of first compound [14]

$$
\text { Coverageoft } t_{R}=\frac{t_{\text {Reference }}-t_{\text {Rfirst }}}{t_{\text {Rlast }}-t_{\text {Rfirst }}} .
$$




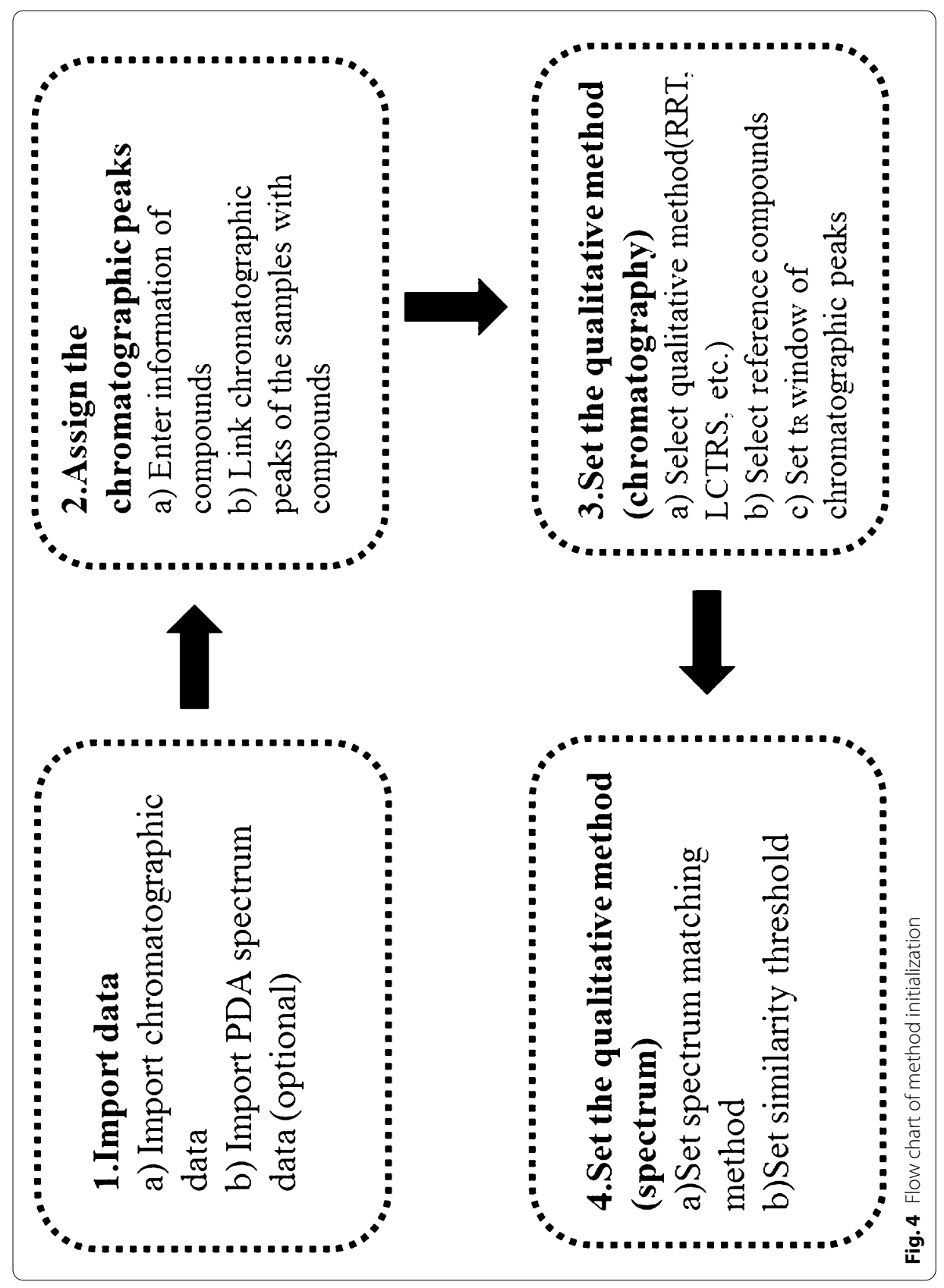




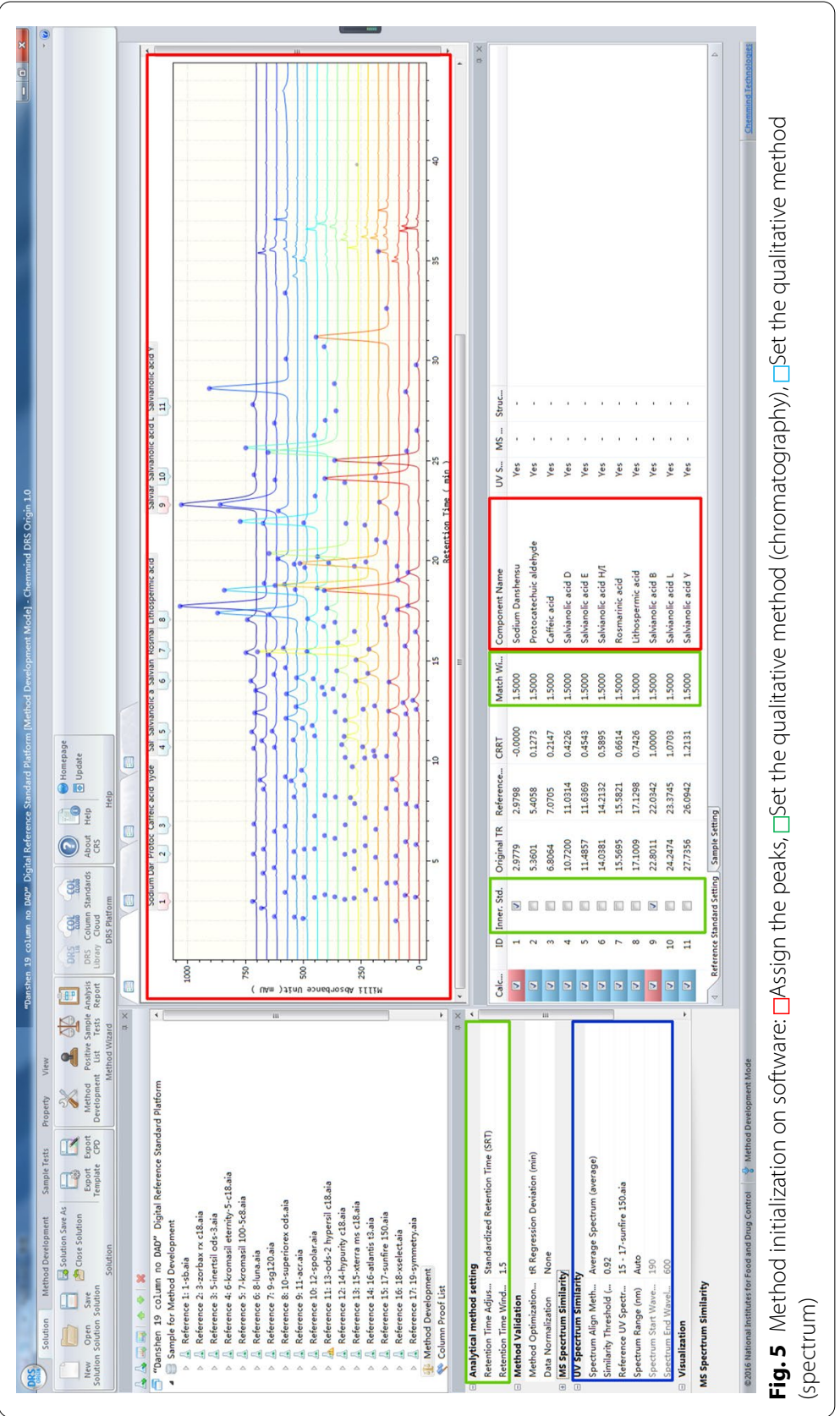


Table 2 Top 10 best reference compound pairs

\begin{tabular}{|c|c|c|c|c|c|c|c|c|c|c|}
\hline $\begin{array}{l}\text { Reference } \\
\text { compound } \\
\text { pairs }\end{array}$ & $\begin{array}{l}\text { Peak3 and } \\
\text { peak9 }\end{array}$ & $\begin{array}{l}\text { Peak2 and } \\
\text { peak9 }\end{array}$ & $\begin{array}{l}\text { Peak3 } \\
\text { and peak8 }\end{array}$ & $\begin{array}{l}\text { Peak3 and } \\
\text { peak10 }\end{array}$ & $\begin{array}{l}\text { Peak2 } \\
\text { and } \\
\text { peak8 }\end{array}$ & $\begin{array}{l}\text { Peak5 and } \\
\text { peak9 }\end{array}$ & $\begin{array}{l}\text { Peak2 } \\
\text { and } \\
\text { peak10 }\end{array}$ & $\begin{array}{l}\text { Peak5 and } \\
\text { peak10 }\end{array}$ & $\begin{array}{l}\text { Peak1 } \\
\text { and peak9 }\end{array}$ & $\begin{array}{l}\text { Peak1 } \\
\text { and peak8 }\end{array}$ \\
\hline $\begin{array}{l}t_{R} \text { deviation / } \\
\text { min }\end{array}$ & 0.258 & 0.271 & 0.274 & 0.277 & 0.286 & 0.292 & 0.294 & 0.304 & 0.304 & 0.305 \\
\hline $\begin{array}{l}\text { Identification } \\
\text { rate/\% }\end{array}$ & 99.5 & 99.5 & 97.3 & 99.5 & 97.3 & 99.5 & 99.5 & 99.5 & 99.5 & 97.3 \\
\hline $\begin{array}{c}\text { The coverage } \\
\text { of } t_{R} / \%\end{array}$ & 64.7 & 71.9 & 43.5 & 70.5 & 50.7 & 45.0 & 77.7 & 50.8 & 82.4 & 61.2 \\
\hline
\end{tabular}

Table 3 Average $t_{R}$ deviation of different compounds

\begin{tabular}{|c|c|c|c|c|c|c|c|c|c|c|c|}
\hline Compounds & 1 & 2 & 3 & 4 & 5 & 6 & 7 & 8 & 9 & 10 & 11 \\
\hline$t_{R}$ deviation /min & 0.267 & 0.120 & - & 0.288 & 0.173 & 0.278 & 0.272 & 0.184 & - & 0.148 & 0.596 \\
\hline
\end{tabular}

$t_{\text {Rreference }}$ is $t_{R}$ of reference compound; $t_{\text {Rlast }}$ is $t_{R}$ of the last compound; $t_{R \text { first }}$ is $t_{R}$ of the first compound [34].

In the present study, 11 marker compounds and a total of 55 reference compound pairs were obtained, among which about 20 pairs were with $t_{R}$ coverage more than $50 \%$. The software's method optimization function provided the top 10 reference compound pairs with the highest accuracy, as shown in Table 2. It was revealed that the $t_{R}$ deviation (average deviation of 11 peaks on $17 \mathrm{col}-$ umns) of the reference compound pair peak 1 and peak 9 was $0.304 \mathrm{~min}$, and the identification rate was $99.5 \%$, ranking 9th. However, the best pair was peak 3 and peak 9, with $t_{R}$ deviation being $0.258 \mathrm{~min}$ and identification rate being $99.5 \%$. In comparison, the optimal combination reduced the deviation by $0.046 \mathrm{~min}$.

\section{Adjustment of $t_{\mathrm{R}}$ window}

Obviously, on one hand, the smaller the $t_{R}$ window, the more accurate the method was, but on the other hand, the fewer the applicable columns were. The optimal $t_{R}$ window could be determined by the statistical results in the software's method optimization function. According to Table 3, which showed the average $t_{R}$ deviation on 17 columns of different peaks, the average $t_{R}$ deviation of No.1 to 10 was less than $0.3 \mathrm{~min}$, but for No.11, it was $0.6 \mathrm{~min}$. Therefore, it might be appropriate to set a $t_{R}$ window of 0.8 min to cover the $t_{R}$ deviation of all peaks.
To verify this value, different $t_{R}$ windows were set; the $t_{R}$ deviation (average deviation of 11 peaks) and identification rates on different columns are summarized in Table 4; Fig. 6. The obtained results revealed that the windows of $0.3 \mathrm{~min}$ and $0.5 \mathrm{~min}$ were so narrow that the identification rate was less than 93\%, and only a few columns were available, with a proportion less than $53 \%$. Furthermore, the identification rates of $1.5 \mathrm{~min}$ and $2.0 \mathrm{~min}$ and the available columns were more than $99 \%$ and $94 \%$, respectively, and the $t_{R}$ window was considerably large; however, there was a risk of misjudgment. It was demonstrated that $0.8 \mathrm{~min}$ and $1.0 \mathrm{~min}$ were near the inflection point, being a good balance for both the accuracy and the applicability. Finally, $0.8 \mathrm{~min}$ was selected.

Each peak can be set its own $t_{R}$ window. For example, a window of 0.8 min could be set for peak 11 and $0.5 \mathrm{~min}$ for the other peaks. Smaller $t_{R}$ windows were used for the other peaks in this study, which further improved the accuracy of the method and reduced the misjudgment rates.

When the PDA spectrum qualitative function was available, the $t_{R}$ window could be widened. In the current study, it was set to $1.5 \mathrm{~min}$ according to the results of Table 4. According to our previous study, $t_{R}$ window was set to $0.5 \mathrm{~min}$ [13], $0.6 \mathrm{~min}, 1.2 \mathrm{~min}$ [14], $0.3 \mathrm{~min}$ [15] and $0.7 \mathrm{~min} \mathrm{[18],} \mathrm{respectively.} \mathrm{Therefore,} \mathrm{when} \mathrm{only} \mathrm{the}$ chromatographic qualitative function was used, the $t_{R}$ 


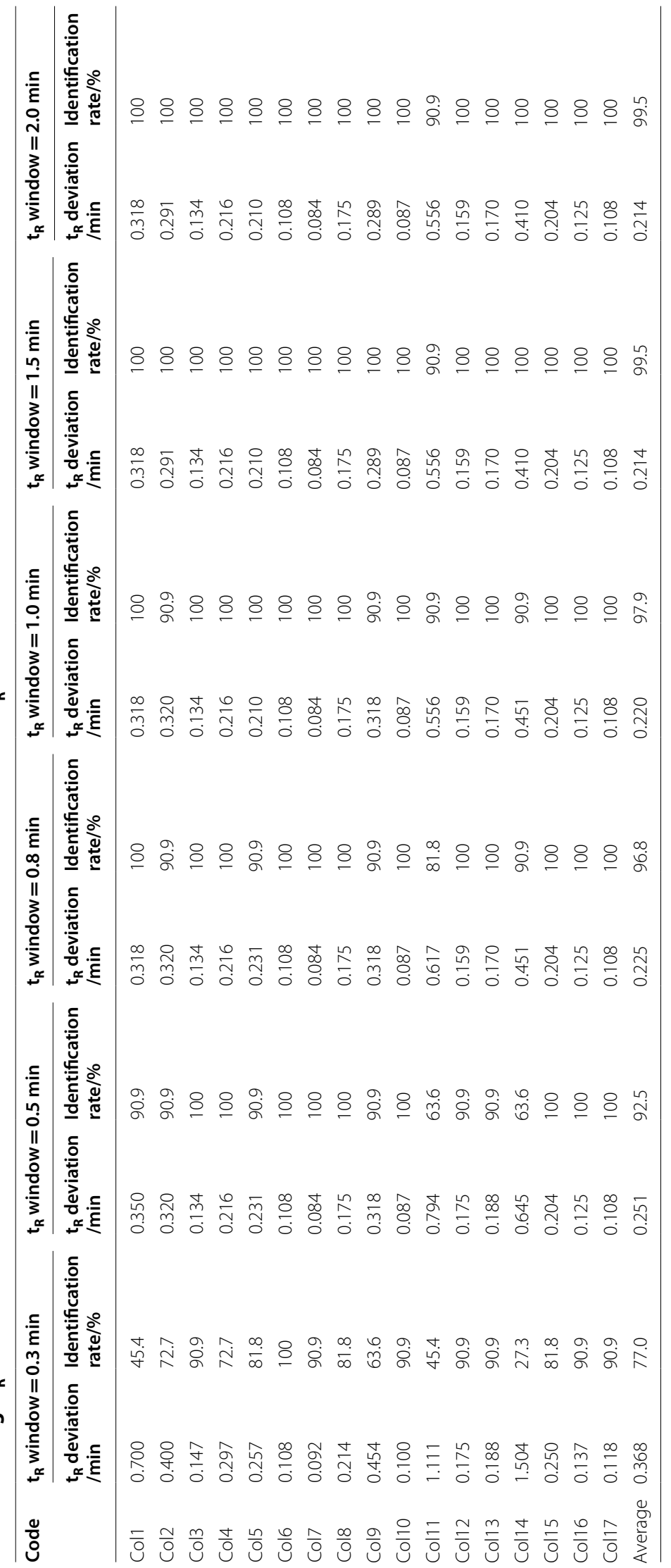



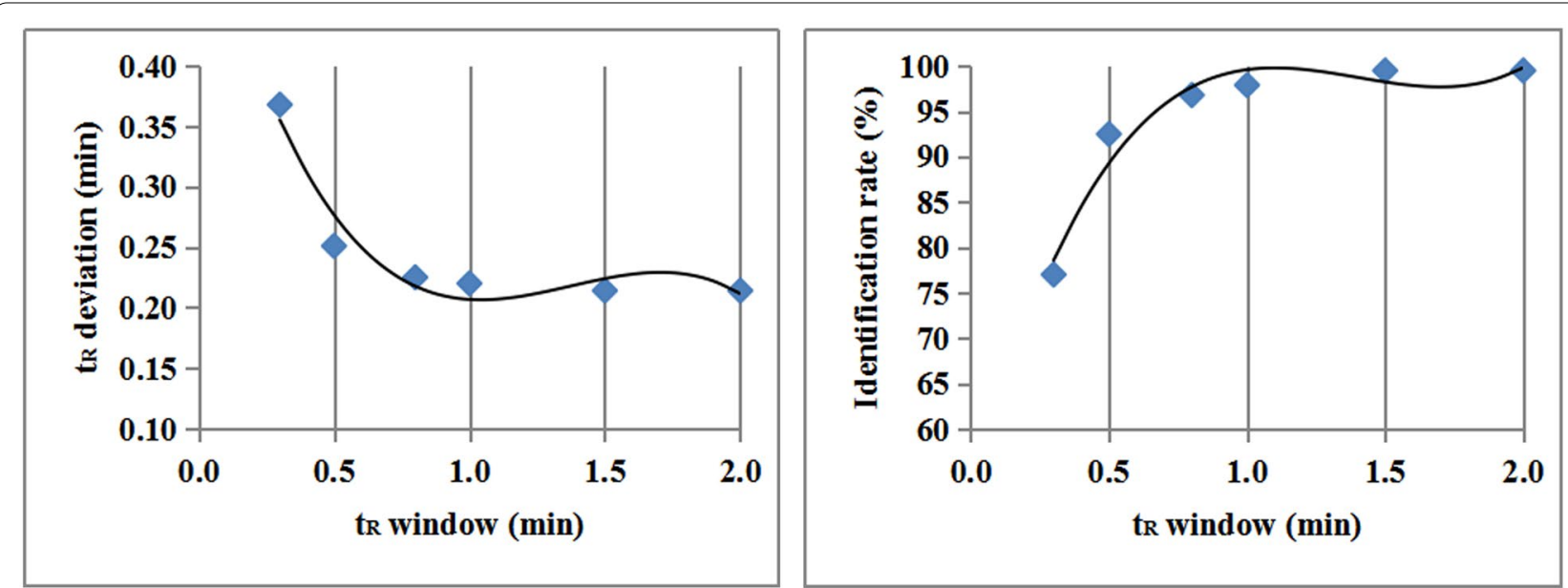

Fig. 6 Trend of $t_{R}$ deviation and identification rate with different $t_{R}$ window

Table 5 Conditions of different methods

\begin{tabular}{|c|c|c|c|c|c|c|c|c|c|c|c|}
\hline Compounds & 1 & 2 & 3 & 4 & 5 & 6 & 7 & 8 & 9 & 10 & 11 \\
\hline $\begin{array}{l}\text { RRT(RRT method, } \\
\text { RRT + PDA } \\
\text { method) }\end{array}$ & 0.174 & 0.316 & 0.423 & 0.644 & 0.679 & 0.830 & 0.910 & $1.000 \mathrm{a}$ & 1.286 & 1.365 & 1.523 \\
\hline $\begin{array}{l}\mathrm{St}_{\mathrm{R}} / \min (\mathrm{LCTRS} \\
\text { method, } \\
\text { LCTRS + PDA } \\
\text { method) }\end{array}$ & 2.980 & 5.406 & $7.071^{\mathrm{a}}$ & 11.030 & 11.640 & 14.210 & 15.580 & 17.130 & $22.030 a$ & 23.370 & 26.090 \\
\hline
\end{tabular}

$t_{R}$ windows of RRT method and LCTRS method were both $0.8 \mathrm{~min}$; for RRT combined with PDA method and LCTRS combined with PDA method, $t_{R}$ windows were both $1.5 \mathrm{~min}$, thresholds were both 0.95

a reference compound

window was recommended to be 0.5 to $1.0 \mathrm{~min}$. However, when the PDA spectrum function was obtained as well, it could be widened to $0.5-1.5 \mathrm{~min}$.

\section{Comparison of different methods}

The software could provide four methods for peak identification, including the RRT method, LCTRS method, RRT combined with the PDA method, and LCTRS combined with the PDA method. The conditions of the four methods optimized according to "3.3.1" and "3.3.2" are shown in Table 5.

Taking Col15 (sunfire C18) as an example, Fig. 7a, b showed the results of RRT and LCTRS combined with PDA methods, respectively. The peak identification results in the red box indicated that Salvianolic acid B was incorrectly identified as Salvianolic acid L by the RRT method. Meanwhile, the two peaks of Salvianolic acid $L$ and Salvianolic acid $Y$ could not be identified due to the large $t_{R}$ deviation. Yet, LCTRS combined with the PDA method, accurately identified all peaks. Additionally, the green box revealed the $t_{R}$ deviation of each peak and the similarity of PDA. The blue box provided linear fitting results of $t_{R}$. The yellow box showed the results of the PDA spectrum. The case suggested that LCTRS combined with the PDA method was superior to the RRT method.

The comparison results of $t_{R}$ from column 1 to 17 by the four optimized methods mentioned above are summarized in Table 6. For the number of positive columns $\left(t_{R}\right.$ deviation $\leq t_{R}$ window and/or PDA similarity $\geq$ similarity threshold), it was demonstrated that LCTRS combined with PDA method was the best, with the smallest average $t_{R}$ deviation, the highest identification rate, and the largest amount of available columns. However, 
a

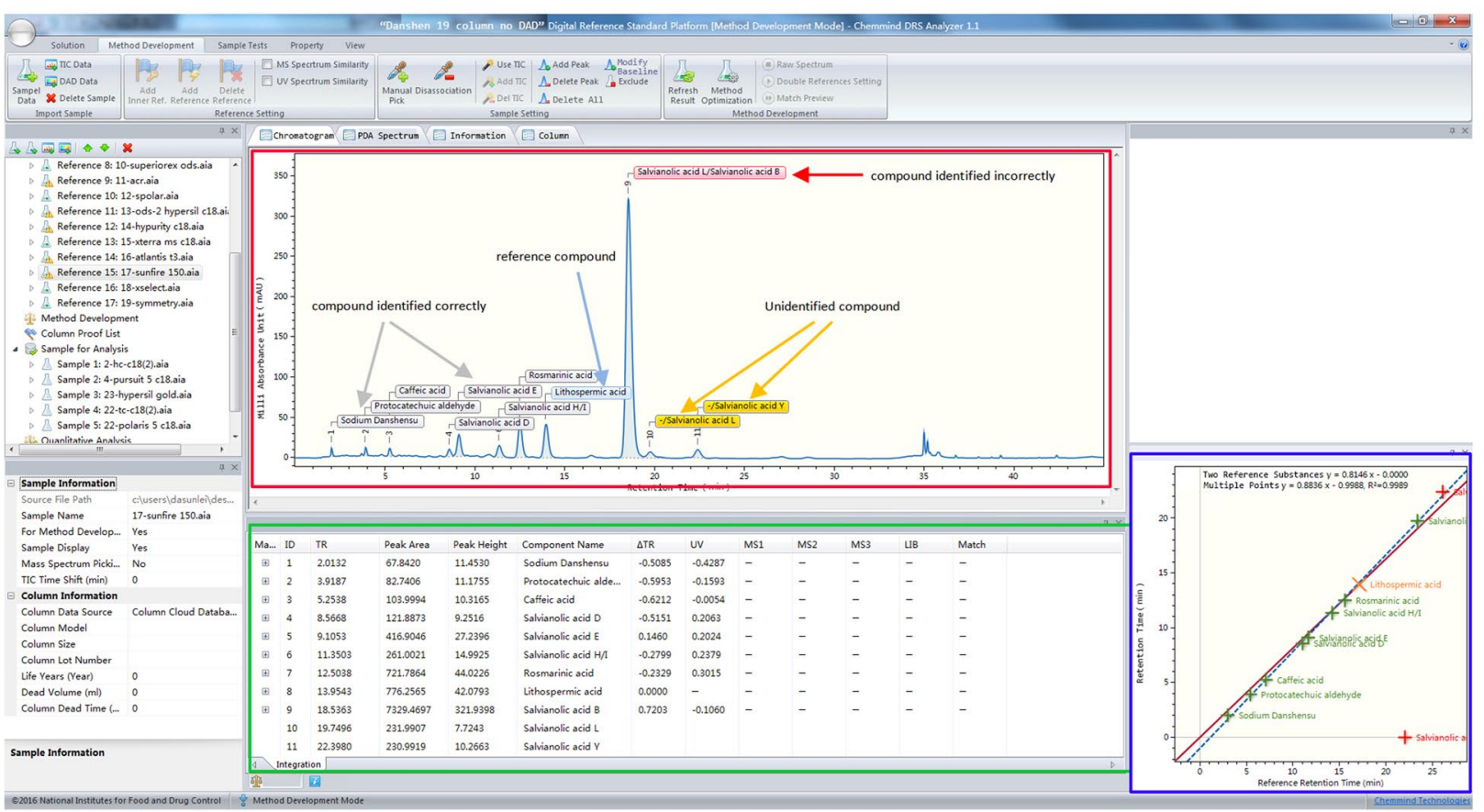

b

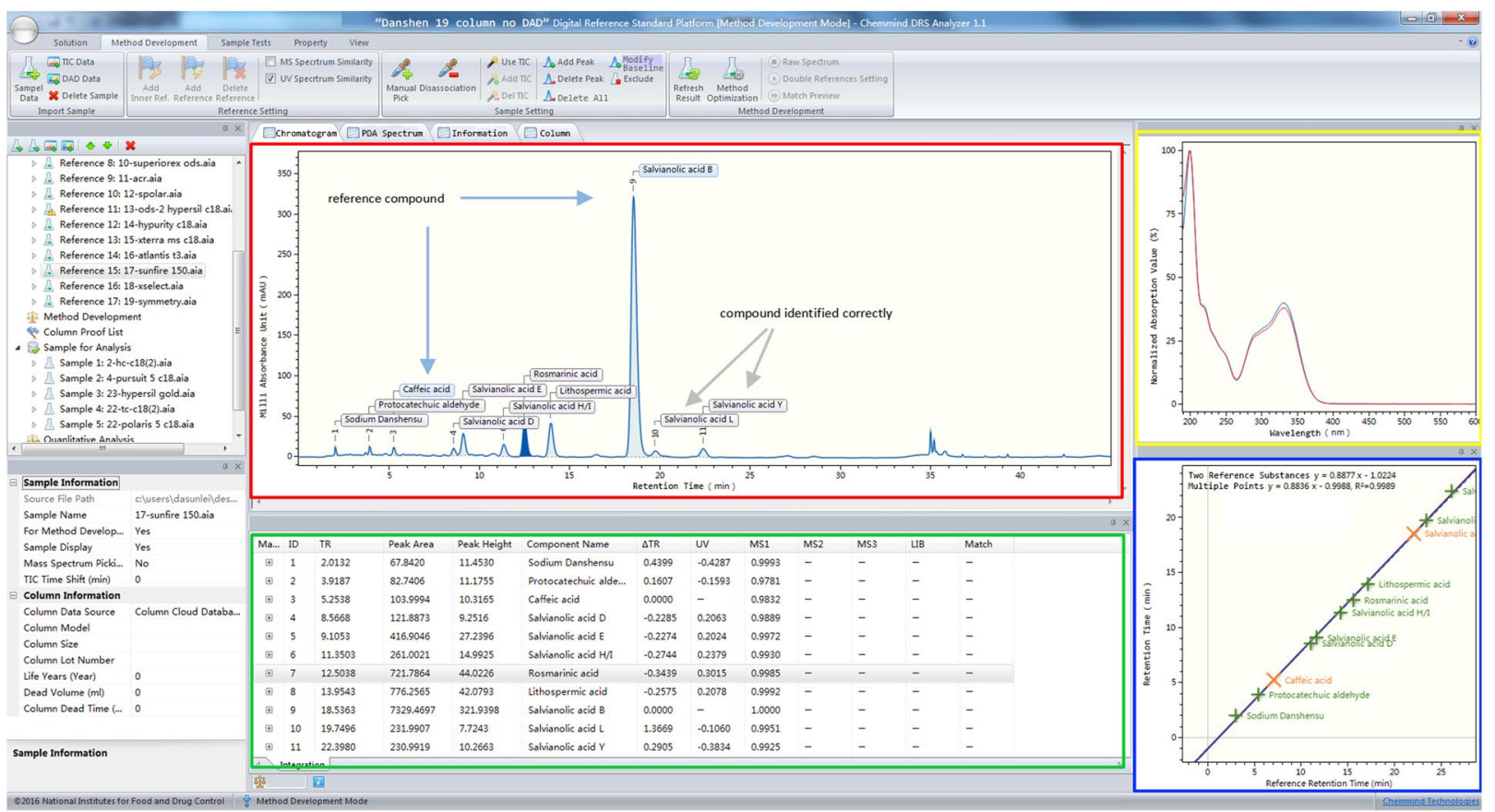

Fig. 7 Comparison of RRT method and LCTRS method on column 15 (WatersSunfire, C18). a The result of the RRT method, b The result of the LCTRS + PDA method ( $\square$ Qualitative analysis result of peaks, $\square$ Information table, $\square$ Linear regression result, $\square$ Spectrum result) 
Table 6 Comparison of different methods (17 columns for method establishment)

\begin{tabular}{llll}
\hline Method & $\begin{array}{l}\text { Average } \mathbf{t}_{\mathbf{R}} \\
\text { deviation } / \mathbf{m i n}\end{array}$ & $\begin{array}{l}\text { Identification } \\
\text { rate/\% }\end{array}$ & $\begin{array}{l}\text { Number } \\
\text { of positive } \\
\text { columns }^{\mathbf{a}}\end{array}$ \\
\hline RRT & 0.401 & 89.8 & 10 \\
LCTRS & 0.225 & 97.5 & 12 \\
RRT + PDA & 0.343 & 96.2 & 12 \\
LCTRS + PDA & 0.214 & 99.5 & 16 \\
\hline
\end{tabular}

a Positive columns were columns on which all peaks could be effectively separated and identified

LCTRS ranked the highest when only the chromatographic algorithm was used.

\section{Sample tests}

Considering the overlap of Salvianolic acid D peak and Salvianolic acid E peak in the chromatogram on columns 18-22, these columns were used for sample testing rather than method establishment. Three steps were included for sample testing. Firstly, the chromatographic and spectral data were introduced, and the peaks were integrated. Secondly, the reference compounds (peak 3 and peak 9) in the sample chromatogram were assigned. Thirdly, the results were obtained after running the method. The sample test results were exhibited in the same way as shown in Fig. 7, which included the qualitative results of peaks, qualitative result tables, linear fitting results, and spectrum. The peak qualitative results on column Agilent TC-C18 (2) of the four methods are shown in Fig. 8 and A shows the results of the RRT method, which had the smallest $t_{R}$ deviation of $0.110 \mathrm{~min}$. Nevertheless, Salvianolic acid B peak was unidentified; Salvianolic acid L peak and Salvianolic acid Y peak were incorrectly identified. Figure $8 \mathrm{~b}$ shows the results of the LCTRS method, which had the second smallest $t_{R}$ deviation of $0.280 \mathrm{~min}$. Salvianolic acid L peak was correctly identified, but the Salvianolic acid Y peak was incorrectly identified. The RRT, combined with the PDA method (Fig. 8c) and the LCTRS combined with the PDA method (Fig. 8d) had the same identified results. As shown in figures, the Salvianolic acid $\mathrm{L}$ peak and Salvianolic acid Y peak were both correctly identified by the two methods. Still, the LCTRS, combined with the PDA method, had a smaller $t_{R}$ deviation of $0.293 \mathrm{~min}$. Table 7 shows a summary of the comparison results of the four methods established on five columns revealing that the RRT method was still the worst method with the lowest identification rate of $72.7 \%$. On the other hand, LCTRS combined with the PDA method remained the optimal method with a smaller $t_{R}$ deviation of 0.240 min and the highest identification rate of $80.0 \%$.

\section{Column recommendation by database}

In the study of the HPLC analysis method, a lot of chromatographic data on different columns are generally collected. However, only the information of column type, such as C18, is provided by the legal standard method. In contrast, data of the brand of the column or related chromatograms are not shown. Nevertheless, these data are indeed valuable, and differences between more useful data (such as with better separation effect, shorter separation time, smaller $t_{R}$ deviation, lower cost of the column) and common data are also meaningful. Therefore, based on the idea of big data, these available data were stored as a part of DRS and used for column recommendation.

Positive and negative columns were defined for column recommendation. Positive columns were referred to columns on which all peaks could be effectively separated and identified. Negative columns were columns on which some peaks could not be separated or identified. In this study, 11 compounds could not be effectively separated on column 21; therefore, this column was considered a negative column for all the four methods (Fig. 8). Column 15 was a positive column for LCTRS combined with the PDA method (Fig. 7b); however, it was negative for the RRT method due to the large retention time deviation of certain compounds (Fig. 7a). For better analysis method reproducibility, future studies should choose the positive column instead of the negative one. For columns that are not on the list of positive or negative columns used, the results, chromatographic data, and PDA spectrum of the column are also meaningful. They can be applied to upgrade and improve the DRS method. Obviously, the positive or negative columns are distinguished for different medicines, different chromatographic conditions, and even for different peak identification methods for the same medicine. The list of the positive and negative columns for the phenolic acid extract of $S$. miltiorrhiza for the four methods is shown in Table 8, while more detailed information is presented on the software database. 


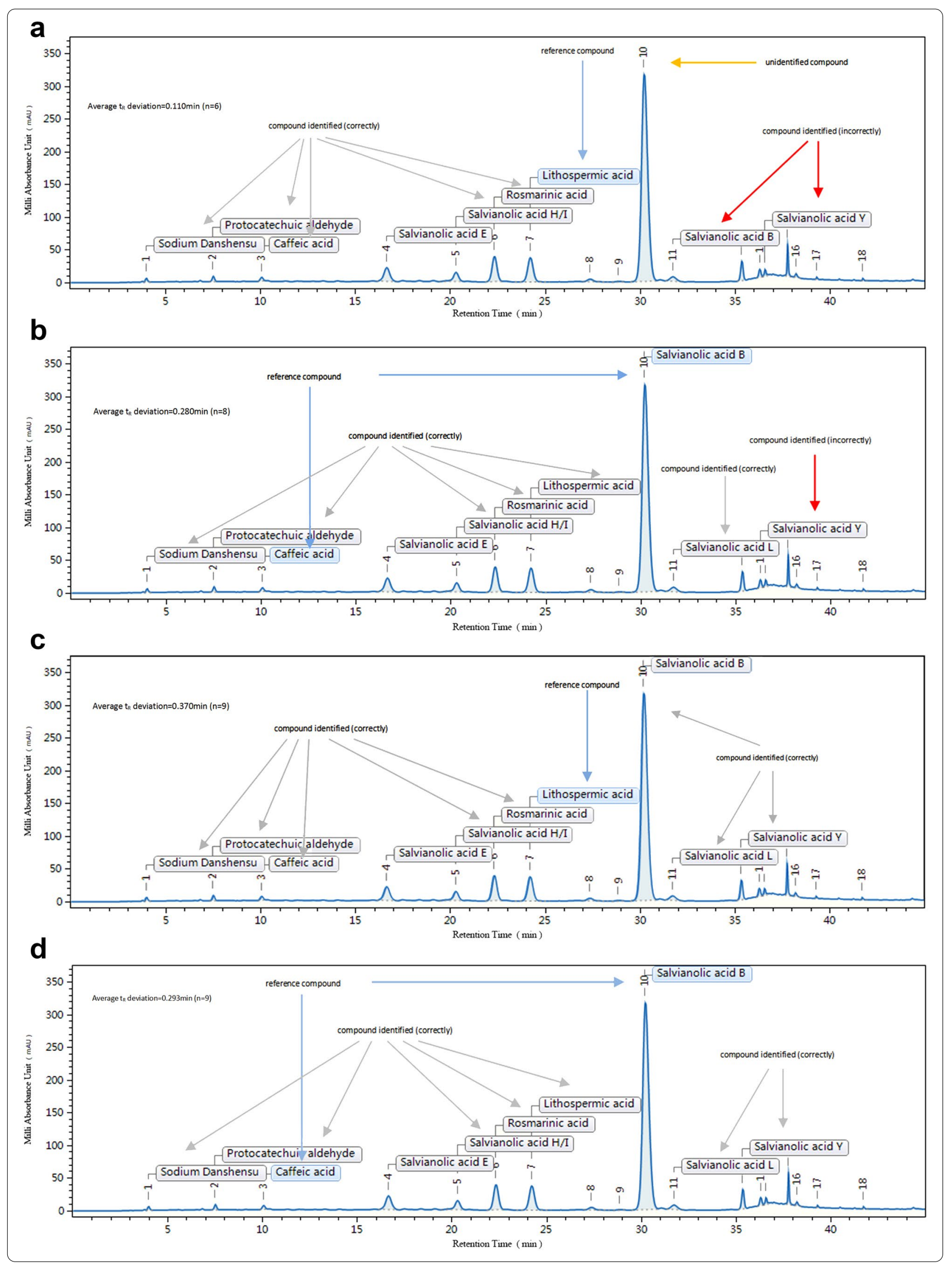


Table 7 Comparison of different methods on five unknown columns, regardless of Salvianolic acid D and Salvianolic acid E

\begin{tabular}{lll}
\hline Method & Average $\mathbf{t}_{\mathbf{R}}$ deviation $/ \mathbf{m i n}$ & $\begin{array}{l}\text { Identification } \\
\text { rate/\% }\end{array}$ \\
\hline RRT & 0.274 & 72.7 \\
LCTRS & 0.185 & 74.5 \\
RRT + PDA & 0.336 & 80.0 \\
LCTRS + PDA & 0.240 & 80.0 \\
\hline
\end{tabular}

\section{Discussion}

In the current study, the offline version of the DRS analyzer was used. In order to improve the convenience of data updating and data sharing, an online version should be developed in the future. The future direction of DRS is expected to be with big data, based on which the artificial intelligence could be introduced. In addition, specifications and the guideline of DRS should be studied in the future so as to ensure the authenticity, accuracy, and reliability.

\section{Conclusions}

To the best of our knowledge, the present study is the first that developed a DRS strategy. A series of quality control methods of fingerprints in the phenolic acid extract of S. miltiorrhiza was developed based on the DRS analyzer, involving the RRT method, LCTRS method, RRT combined with PDA spectrum method, and LCTRS combined with PDA spectrum method. In addition, the column database of samples was also established. The obtained results revealed the LCTRS combined with the PDA spectrum as an optimal way. The results also demonstrated that DRS analyzer could accurately identify 11 compounds of the samples, using only one or two physical RSs. The strategy significantly reduced the analysis cost and ensured the accuracy and reproducibility of the analysis method.

The DRS strategy adopted in this study has the following advantages. (1) the software automatically processes data, instead of the complex manual calculation, thus saving time and avoiding mistakes in calculation than RRT method and LCTRS method. (2) The results are objective and consistent, avoiding the subjectivity of manual identification than RRT method, ERS method, and LCTRS method. (3) The chromatographic and spectral data formats supported by the software are universal and compatible with mainstream chromatograph workstations; therefore, the popularization and application of the method can be easily realized. (4) It is compatible with a variety of substitute RS methods (such as RRT

Table 8 Column recommendations for different methods

\begin{tabular}{|c|c|c|c|c|}
\hline Code & $\begin{array}{l}\text { Recommendation for RRT } \\
\text { method }\end{array}$ & $\begin{array}{l}\text { Recommendation } \\
\text { for LCTRS method }\end{array}$ & $\begin{array}{l}\text { Recommendation for RRT combined } \\
\text { with PDA method }\end{array}$ & $\begin{array}{l}\text { Recommendation for LCTRS } \\
\text { combined with PDA method }\end{array}$ \\
\hline Col1 & Negative & Positive & Negative & Positive \\
\hline Col2 & Negative & Negative & Negative & Positive \\
\hline Col3 & Positive & Positive & Positive & Positive \\
\hline Col4 & Positive & Positive & Positive & Positive \\
\hline Col5 & Positive & Negative & Positive & Positive \\
\hline Col6 & Positive & Positive & Positive & Positive \\
\hline Col7 & Positive & Positive & Positive & Positive \\
\hline Col8 & Positive & Positive & Positive & Positive \\
\hline Col9 & Negative & Negative & Positive & Positive \\
\hline Col10 & Positive & Positive & Positive & Positive \\
\hline Col11 & Negative & Negative & Negative & Negative \\
\hline Col12 & Negative & Positive & Positive & Positive \\
\hline Col13 & Positive & Positive & Positive & Positive \\
\hline Col14 & Negative & Negative & Negative & Positive \\
\hline Col15 & Negative & Positive & Positive & Positive \\
\hline Col16 & Positive & Positive & Positive & Positive \\
\hline Col17 & Positive & Positive & Positive & Positive \\
\hline Col18 & Negative & Negative & Negative & Negative \\
\hline Col19 & Negative & Negative & Negative & Negative \\
\hline Col20 & Negative & Negative & Negative & Negative \\
\hline Col21 & Negative & Negative & Negative & Negative \\
\hline Col22 & Negative & Negative & Negative & Negative \\
\hline
\end{tabular}


method, ERS method, and LCTRS method) and supports chromatographic algorithms, spectrum algorithms, and the combination of these algorithms, which has complementary advantages of each method. (5) DRS analyzer is based on the idea of big data to realize the recommendation of the column for different medicines, different chromatographic conditions and different peak identification methods (such as RRT method and LCTRS method) for the same medicine.

In summary, the DRS strategy can effectively reduce the cost of RSs, and achieve higher accuracy and reproducibility than the single substitute RS method. Moreover, it is automated, intelligent, objective, accurate, eco-friendly, universal, sharing, and promising, thus representing a feasible method for overall quality control (such as fingerprint analysis and simultaneous multi-components determination) of TCMs and herbal medicines on different chromatographic columns.

\section{Abbreviations}

TCMs: Traditional Chinese Medicines; RS: Reference standards; ERS: Extractive reference substance; DRS: Digital reference standard; RRT: Relative retention time; LCTRS: Linear calibration using two reference substances; PDA: Photon diode array; $\mathrm{t}_{\mathrm{R}}$ : Retention time.

\section{Acknowledgements \\ Not applicable.}

\section{Authors' contributions}

LS and SCM designed the study. LS and RTT designed and wrote the program. QJW, XLY and LS conducted the experiments. QJW, XLY, LS and HZH analyzed the data. QJW, XLY and LS wrote the manuscript. SCW and SCM revised the manuscript. All authors read and approved the final manuscript.

\section{Funding}

This study was supported by National Natural Foundation of China (81303214).

\section{Availability of data and materials}

All data are fully available without restriction.

Ethics approval and consent to participate

Not applicable.

\section{Consent for publication}

Not applicable.

\section{Competing interest}

The authors declare that they have no competing interests.

\section{Author details}

${ }^{1}$ National Institutes for Food and Drug Control, Beijing, China. ${ }^{2}$ Fangshan District Market Supervision and Administration, Beijing, China. ${ }^{3}$ Xinjiang Institute for Drug Control, Urumqi, China. ${ }^{4}$ Xi'an Jiaotong University, School of Medicine, Xi'an, China. ${ }^{5}$ Chemmind Technologies Co., Ltd, Beijing, China.

Received: 14 September 2020 Revised: 14 November 2020 Accepted: 26 November 2020

Published online: 11 January 2021
References

1. Zheng GD, Yang XJ, Chen BZ, Chao YX, Hu PJ, Cai Y, Wu B, Wei MY. Identification and determination of chemical constituents of Citrus reticulata semen through ultra high performance liquid chromatography combined with Q Exactive Orbitrap tandem mass spectrometry. J Sep Sci. 2020;43:438-51.

2. Liu XY, Jiang WW, Su M, Sun Y, Liu HM, Nie L, Zang HC. Quality evaluation of traditional Chinese medicines based on fingerprinting. J Sep Sci. 2020;43:6-17.

3. Xiong J, Zheng TJ, Shi Y, Wei F, Ma SC, He L, Wang SC, Liu XS. Analysis of the fingerprint profile of bioactive constituents of Traditional Chinese medicinal materials derived from animal bile using the HPLC-ELSD and chemometric methods: an application of a reference scaleplate. J Pharm Biomed Anal. 2019;174:50-6.

4. He L, Shi X, Seto SW, Dennis C, Wang H, Zhang S, Chen W, Wang J. Using 3D-UPLC-DAD and a new method-verification by adding mixture standard compounds to determine the fingerprint and eight active components of Naoluoxintong decoction. J Pharm Biomed Anal. 2019;169:60-9.

5. Pang $Y$, Sun L, Jin HY, Ma SC. Discussion on application and technical requirements of substitute reference substance method for simultaneous determination of multi-components in traditional Chinese medicine. Chin J Pharm Anal. 2013;33:169-77.

6. Lei S, Jin HY, Ma SC, Dai Z, Cheng YY, Qian ZZ. Guideline of substitute $\mathrm{i} 1 \mathrm{H}^{2}$ eference substance method for evaluation of traditional chinese medicines. Chin J Pharm Anal. 2015;50:284-6.

7. Chen AZ, Sun L, Yuan H, Wu AY, Lu JG, Ma SC. A holistic strategy for quality and safety control of traditional Chinese medicines by the ivarious standard system. J Pharm Anal. 2017;7:271-9.

8. Xie PS, Ma SC, Tu PF, Wang ZT, Stoeger E, Bensky D. The Prospect of Application of Extractive Reference Substance of Chinese Herbal Medicines. Chin Med. 2013;4:125-36.

9. Chinese Pharmacopoeia Commission. Chinese Pharmacopoeia. Edition 2015, Volumea I [S]. 2015.

10. European Pharmacopoeia 10.0. European Pharmacopoeia Commission. 2020

11. U.S. Pharmacopeia 43/ National Formulary 38. The United States Pharmacopeial Convention. 2020

12. Department of Health Hong Kong Special Administrative. Region The People's Republic of China,Hong Kong Chinese Materia Medica Standards. Vol 3[S]. 2012.

13. Sun L, Jin HY, Pang Y, Ma SC. Two reference substances for determination of multiple components I-Linear calibration using two reference substances for identification of chromatographic peaks. Chin J Pharm Anal. 2013;33:1424-30.

14. Sun L, Jin HY, Tian RT, Wang MJ, Liu LN, Ye LP, Zuo TT, Ma SC. A simple method for HPLC retention time prediction: linear calibration using two reference substances. Chin Med. 2017;12:16-27.

15. Chen $A Z$, Sun L, Yuan H, Wu AY, Lu JG, Ma SC. Simultaneous qualitative and quantitative analysis of 11 active compounds in rhubarb using two reference substances by UHPLC. J Sep Sci. 2018;41:3686-96.

16. LiW, Hu CQ. Spectral correlation of high-performance liquid chromatography-diode array detection data from two independent chromatographic runs peak tracking in pharmaceutical impurity profiling. J Chromatogr A. 2008;1190:141-9.

17. Chen ZZ, Zhang DS, Wang N, Feng F, Hu CQ. Identification of impurity peaks in the HPLC chromatogram by LC-MS and two-dimensional chromatographic correlation spectroscopy. Yao Xue Xue Bao. 2012;47:492-7.

18. Liu LN, Sun L, Tian RT, Jin HY, An Y, Ma SC. Fingerprint Analysis of SWERTIA CHIRATA by linear calibration using two reference substances combining with PDA assistant. Chin Pharm J. 2015;50:287-92.

19. He Y, Li Q, Bi K. Simultaneous Determination of Six Active Components by a single standard to determine multicomponents combined with fingerprint analysis for the quality control of Rhizoma Chuanxiong. J Sep Sci. 2015;38:1090-9.

20. Fang J, Yang B, Ge Z, Bai X, Yan B. Single Standard substance for the determination of nine volatile components in the distillate of fructus gardeniae and radix curcumae (An Intermediate of Xingnaojing Injection). J Sep Sci. 2017:40:3946-57.

21. Wang W, Ma X, Guo X, Zhao M, Tu P, Jiang Y. A series of strategies for solving the shortage of reference standards for multi-components determination of traditional chinese medicine, Mahoniae caulis as a case. J Chromatogr A. 2015;1412:100-11. 
22. Wang F, Wang B, Wang L, Xiong ZY, Gao W, Li P, Li HJ. Discovery of discriminatory quality control markers for chinese herbal medicines and related processed products by combination of chromatographic analysis and chemometrics methods: radix scutellariae as a case study. J Pharm Biomed Anal. 2017;138:70-9.

23. Wu TJ, LU J, Ni H, Li P, Jiang Y, Li HJ. Construction of an optimized method for quality evaluation and species discrimination of coptidis rhizoma by ion-pair high performance liquid chromatography combined with response surface methodology. J Pharm Biomed Anal. 2018;153:152-7.

24. Liu W, Zhang J, Han W, Liu Y, Feng J, Tang C, Feng N, Tang Q. One Single Standard Substance for the Simultaneous Determination of 17 Triterpenes in Ganoderma Lingzhi and its related species using high-performance liquid chromatography. J Chromatogr B Analyt Technol Biomed Life Sci. 2017;1068-1069:49-55.

25. Yu XA, Li J, Azietaku JT, Liu W, He J, Chang YX. A single standard to determine multi-components method coupled with chemometric methods for the quantification, evaluation and classification of notopterygii Rhizoma Et Radix From different regions. Molecules. 2019;24:3574-94.

26. Snyder LR, Dolan JW, Carr PW. A new look at the selectivity of RPC columns. The hydrophobic subtraction model evaluates the selectivity of HPLC reversed-phased columns so that researchers can choose a suitable substitute or a sufficiently orthogonal second column. Anal Chem. 2007;79:3254-62

27. Gilroy JJ, Dolan JW, Snyder LR. Column selectivity in reversed-phase liquid chromatography: IV. Type-B alkyl-silica columns. J Chromatogr A. 2003;1000:757-78.

28. Dehouck P, Visky D, Vander Heyden Y, Adams E, Kovács Z, Noszál B, Massart DL, Hoogmartens J. Characterisation of reversed-phase liquidchromatographic columns by chromatographic tests: comparing column classification based on chromatographic parameters and column performance for the separation of acetylsalicylic acid and related compounds. J Chromatogr A. 2004;1025:189-200.

29. Snyder LR, Dolan JW, Carr PW. The hydrophobic-subtraction model of reversed-phase column selectivity. J Chromatogr A. 2004;1060:77-116.
30. Dragovic S, Haghedooren E, Németh T, Palabiyik IM, Hoogmartens J, Adams E. Evaluation of two approaches to characterise liquid chromatographic columns using pharmaceutical separations. J Chromatogr A. 2009;1216:3210-6.

31. Wang QJ, Sun L, Liu F, Jin HY, Yu JD, Dai Z, Ma SC. Progress and Challenges of reference standard and its new form: digital reference standard. Chinese Medicine. Chin Med. 2016;7:77-91.

32. ASTM Standards. Standard specification for analytical data interchange protocol for chromatographic data: E1947-98[S]. West Conshohocken,PA: ASTM International, 2009.

33. Cheng YY, Chen MJ, Wu YJ. Measures for determining the similarity of chemical fingerprint and a method of evaluating the measures. Acta Chim Sinica. 2002;60:2017-21.

34. Sun L, Ye LP, Yu XL, Hong W, Li G, Ma SC. Optimal selection of reference compound for HPLC relative retention time. Chin J Pharm Anal. 2020;40:421-9.

\section{Publisher's Note}

Springer Nature remains neutral with regard to jurisdictional claims in published maps and institutional affiliations.
Ready to submit your research? Choose BMC and benefit from:

- fast, convenient online submission

- thorough peer review by experienced researchers in your field

- rapid publication on acceptance

- support for research data, including large and complex data types

- gold Open Access which fosters wider collaboration and increased citations

- maximum visibility for your research: over $100 \mathrm{M}$ website views per year

At BMC, research is always in progress.

Learn more biomedcentral.com/submissions 